\title{
Review Article \\ Recent Developments and Research Issues in Microultrasonic Machining
}

\author{
Vivek Jain, Apurbba Kumar Sharma, and Pradeep Kumar \\ Mechanical and Industrial Engineering Department, Indian Institute of Technology Roorkee, Roorkee, Uttarakhand 247667, India \\ Correspondence should be addressed to Apurbba Kumar Sharma, akshafme@iitr.ernet.in
}

Received 20 January 2011; Accepted 13 February 2011

Academic Editors: V. P. Astakhov, S. Cartmell, and K.-H. Chang

Copyright () 2011 Vivek Jain et al. This is an open access article distributed under the Creative Commons Attribution License, which permits unrestricted use, distribution, and reproduction in any medium, provided the original work is properly cited.

Demand for micromachining has been on the rise in recent years owing to increasing miniaturization. Production of parts in microscale, especially with brittle materials, is challenging. Ultrasonic micromachining has been gaining popularity as a new alternative in fabrication of such parts. The process gives a machining option for geometrically challenging and/or brittle material parts that are difficult to machine by conventional processes. In the recent years, possibilities have been explored to improve the "Unit Removal" in microultrasonic machining (micro-USM). However, the research in the area is yet to attain momentum. The present paper is an attempt to present the state of the art in the area of micro-USM based on the literature. Developments in the critical areas of the process like machine tool technology, machining tool head, transducers, and precision attainable in the process with challenges have been discussed. Potential research issues have been explored for future work. Possible application areas have been identified.

\section{Introduction}

Miniaturization has been one of the major themes in manufacturing in the recent years after "automation" took the researches and industries the same way during the last quarter of the previous century. Research publications in the area of micromachining started appearing since the end of the last decade, and in fact, got the momentum with the unfolding of the new century, mostly driven by industry needs. Miniaturized components and products have been in strong demand because of their unique advantages such as less space requirement, less energy and material consumption, easeness in carrying, and/or handling and can be cheaper. The growth of Micro Electro Mechanical Systems (MEMS) and the related research in different industries such as electronics, optics, medical, biotechnology, automotive, communications, and avionics are largely attributed to these microcomponents. But product miniaturization poses multiple challenges and demands innovations as well as continuous improvements in manufacturing technologies to ensure the processing of a wide range of materials [1]. Hence micromachining is considered as one of the key enablers to solve these issues and consequently, in great demand. Research is active in this area to characterise new technologies or to improve known processes to guarantee fine precisions and low costs of manufacturing, so as to facilitate a real growth and diffusion in the industrial world. Several research issues associated with micromachining starting from standard lithographic methods to nontraditional technologies and mechanical micromachining techniques have been reported [2].

Bulk micromachining, which utilizes deep etching techniques, was developed and used to produce pressure sensors, accelerometers and ink nozzles [3]. The basic scheme for surface micromachining was developed and introduced in 1983 [4]. In the 1980s, the LIGA (Lithographie Galvanoformung Abformung) process was developed in Germany [5] and became popular because it can be used to make parts or moulds from electroplatable materials or use the moulds to make injection moulded plastics. While these techniques can be used for mass production in microchip manufacturing, industrial applications for complex threedimensional systems in microscale are still limited by materials, geometrical limits, and fabrication process costs and time. Bulk micromachining has the disadvantage that the devices are generally relatively large and therefore consume 
most of the chip area [6]. In regard to LIGA, minor precisions and aspect ratios are the limits of the process.

Tool-based micromachining methods such as microturning, micromilling, and microgrinding are capable of generating 3D free-form features with micron level accuracy. Despite its potential, practical use of mechanical microcutting is limited by the low tool/machine stiffness and cutting tool strength, especially for hard materials such as heat-treated mold, die steels, and ceramics $[7,8]$. One solution to this problem is to employ nontraditional machining techniques which are also being developed in microscopic scale in order to achieve real 3D sculptured complex components. Interesting methods are, in particular, laser micromachining, micro-electrodischarge machining (micro-EDM), microelectrochemical machining (micro-ECM), and micro-USM.

Glass, silicon, and polymers are the most common micromachined materials using lasers $[9,10]$. Ink jet printer nozzles are an example of devices manufactured by excimer laser micromachining [11]. Micro-electrodischarge machining is commonly used to microdrill or to pattern trenches in workpieces, with a micromilling approach and simple-shaped tools $[12,13]$. Circular rotating micro-tools are mainly adopted and on-the-machine made in order to avoid off-centering and tilting errors. Further, the problem of imprecision associated with tool rechucking on tool holder is significantly minimized, improving at the same time roundness quality during machining. The area is strengthened by the emergence of micro-electrochemical machining that appears to be a very promising micromachining technology due to its advantages that include high MRR and rapid machining time. It also permits machining of chemically resistant materials like titanium, copper alloys, super alloys, and stainless steel, which are widely used in biomedical, electronic, and MEMS applications [14]. Despite the significant benefits of these techniques, important issues like (i) the presence of a heat affected zone (HAZ) and (ii) thermal stresses in the micromachined part in case of laser micromachining [15] and micro-EDM are yet to be solved. Machining time and material removal rates are mainly limited by small discharge energies in micro-EDM [16]. In micro ECM, on the other hand, the dissolution rate of the metal workpiece decreases as the machining depth increases on account of the difficulty of maintaining the flow of electrolyte deep inside the microhole [17]. The flow space of the electrolyte and electrolyte diffusion was improved via the application of ultrasonic vibrations. Some improvements in machining efficiency are also obtainable with ultrasonic tool or workpiece vibration while superimposed during micro-EDM drilling operations, in relation to the better removal of debris $[18,19]$. Since ultrasonic vibration complements other nontraditional processes, special attention is required to the role of microultrasonic machining. Thus, an attempt has been made to present a detailed review of the developments in the area of micro-USM process and various research issues involved in making the process more pragmatic. Significantly less published data in the area of micro-USM indicates that the area is yet to be well explored. However, research activities in the area have been increasing in the current decade.

\section{Micro-USM Process}

Micro-USM is basically evolved from macro-USM, which has been already investigated and reported widely. MicroUSM as one of the nontraditional manufacturing processes finds its main advantage in machining nonconductive, hard, and brittle materials and capability of generating surface free of thermal damage. Table 1 presents a comparison between different micromachining techniques. The micro-USM process, as observed from the table, can be compared to almost all other micromachining processes. This process has the edge over the highly competitive LIGA process as far as 3D profile machining is concerned apart from applicable to a broad range of work materials.

2.1. Historical Development. Ultrasonic machining is a relatively old machining technique whose basis was laid way back in 1927 and was patented by L. Balamuth in 1945. The technology that has evolved since then has been variously termed "ultrasonic machining", "impact grinding", or "slurry drilling" and relies on the cutting action of an abrasive slurry flowing between the vibrating tip of a transducer and a workpiece. It is a technology that has attained a recognized status in manufacturing technology and found increasing applications in industries including aerospace, optics, and automotive [20]. The first USM tools, mostly mounted on the bodies of drilling and milling machines, had been built by 1953-1954. By 1960, independent USM tools of various types were commercialised and came into regular production for a variety of applications [21]. The first attempt of downsizing macro-USM for micromachining was conducted by Masuzawa of Tokyo University in the mid 1990s [22]. The micro-USM is used for machining hard and brittle materials. Typical workpiece materials being machined in previous experimental investigations include glass, silicon, and alumina $[23,24]$. Micro-USM has a set of process parameters similar to macro-USM. However, the downsizing for micromachining requires a microsized tool (or tool feature), smaller amplitude, and microsized abrasive particles. A comparison of the micro-USM and macro-USM parameters is presented in Table 2.

2.2. Process Principle. Figure 1 illustrates a basic setup of a micro-USM process. The set up primarily consists of a tool system and slurry supply unit. The micro-USM employs the mechanical vibration of the ultrasound with a frequency within the range of 20 to $40 \mathrm{kHz}$. The tool is mechanically vibrated at an ultrasonic frequency and amplitude of few micrometers. The abrasive slurry, a mixture of irregularshaped fine abrasive particles (usually, in the range of (0.5 $5 \mu \mathrm{m})$ ), and a liquid medium is fed into the gap between the tool and workpiece. As the vibrating tool head hits the free abrasives in the slurry, they attain momentum and impact upon the target workpiece location. A localized fatigue stress is developed in the impact zone owing to continued impact, and microchipping occurs resulting in material removal. Moreover, a small amount of material removal might also be contributed by the mechanical abrasion of the hard 
TABLE 1: Common attributes of different micromachining techniques $[2,3,8]$.

\begin{tabular}{|c|c|c|c|c|c|c|c|}
\hline \multirow{2}{*}{ Features } & \multicolumn{7}{|c|}{ Micromachining techniques } \\
\hline & Bulk-surface & LIGA & Laser & Micro-EDM & Micro-ECM & Micromilling & Micro-USM \\
\hline $\begin{array}{l}\text { Minimum } \\
\text { Dimension }\end{array}$ & + & ++ & ++ & ++ & + & + & ++ \\
\hline Accuracy & + & ++ & \pm & + & + & \pm & + \\
\hline Aspect ratio & - & ++ & \pm & \pm & \pm & \pm & \pm \\
\hline MRR & $\begin{array}{l}\text { Depends upon } \\
\text { process }\end{array}$ & $\begin{array}{l}\text { Depends upon } \\
\text { process }\end{array}$ & + & ++ & + & + & + \\
\hline $\begin{array}{l}\text { Thermal damage } \\
\text { to the surface }\end{array}$ & No & No & Yes & Yes & Yes & Yes & No \\
\hline $\begin{array}{l}\text { Geometrical } \\
\text { freedom }\end{array}$ & $2 \mathrm{D}$ & $2 \mathrm{D}$ & $3 \mathrm{D}$ & $3 \mathrm{D}$ & $3 \mathrm{D}$ & $3 \mathrm{D}$ & $3 \mathrm{D}$ \\
\hline Material & $\begin{array}{l}\text { Very limited } \\
\text { material suite }\end{array}$ & $\begin{array}{l}\text { Very limited } \\
\text { material suite }\end{array}$ & $\begin{array}{c}\text { Metal, } \\
\text { polymers, } \\
\text { ceramics }\end{array}$ & $\begin{array}{c}\text { Only } \\
\text { conductive } \\
\text { materials }\end{array}$ & $\begin{array}{c}\text { Only } \\
\text { conductive } \\
\text { materials }\end{array}$ & Metal, polymer & $\begin{array}{c}\text { Conductive, } \\
\text { nonconductive, } \\
\text { hard, and brittle } \\
\text { materials }\end{array}$ \\
\hline
\end{tabular}

++ Very good; + good; \pm fair.

TABLE 2: Features of macro- and micro-USM.

\begin{tabular}{lll}
\hline Parameters & Micro-USM & Macro-USM \\
\hline $\begin{array}{l}\text { Vibration frequency, } \\
\mathrm{kHz}\end{array}$ & Usually $>20$ & Usually $>20$ \\
Vibrated part & Tool or Workpiece & Tool \\
Amplitude, $\mu \mathrm{m}$ & Within microns & $\begin{array}{l}\text { Tens of microns } \\
(8 \sim 30)\end{array}$ \\
$\begin{array}{l}\text { Abrasive particle size, } \\
\mu \mathrm{m}\end{array}$ & Within microns & $\begin{array}{l}\text { Tens of microns } \\
(0.5 \sim 5)\end{array}$ \\
$\begin{array}{l}\text { Static load } \\
\text { Tool/feature Size, } \mathrm{mm} \\
\text { (End diameter) }\end{array}$ & Gram force & Kilogram force \\
\hline
\end{tabular}

microabrasives. Further, implosion of the gas bubbles, also called cavitation, can play a key role in material removal at microlevel. Although water is usually preferred as the slurry medium, there exists a possibility that the chemical impurities present in the slurry medium can selectively cause instantaneous degradation of the work material resulting in loss of material. A continuous flow of slurry flushes away the debris from the machining zone and refills the gap with fresh slurry.

Thus, based on the understanding of macro-USM research, the contributing mechanisms in case of microUSM can be summarized into four categories:

(i) microchipping by impact of the free moving abrasive particles,

(ii) mechanical abrasion by the abrasive particles against the workpiece surface,

(iii) cavitation effects in liquid agitated by ultrasonic vibration,

(iv) chemical actions associated with the liquid being employed.

\section{Developments in Micro-USM Machine Tools and Tool Head}

The variants in micro-USM can be categorised as shown in Figure 2. While Figure 2(a) presents a classification based on the machine tool characteristics, Figure 2(b) shows some variations in the micro-USM according to different tool heads used. The first type of micro-USM originates from the concept of "micromachining using microtool" [24, 25] in which there is no rotary motion involved. A simple cylindrical tool was used, and the vibration was given to the microtool. As USM is associated with a major drawback of tool wear, this kind of tooling causes continuous shortening of tool length and, therefore, imposes obstacles in maintaining consistent vibration amplitude at the tool tip. The vibration amplitude varies at different locations along the tool axis, and tool wear changes the location of the tool tip causing the inconsistency. Applying ultrasonic vibration to the workpiece has been found to be preferable because it eliminates the influence of tool wear on the vibration amplitude of tool tip in case of applying vibration to the tool. Furthermore, the vibrated workpiece may help in stirring the abrasive slurry during machining to increase the efficiency of abrasive particles around the machining zone and remove debris [26].

Rotary ultrasonic machining (RUM), as indicated in Figure 2(a), is one of the cost-effective and hybrid machining processes available for drilling holes. It merges the material removal mechanisms of diamond grinding and USM, resulting in higher material removal rate (MRR) than that obtained by either diamond grinding or USM [27]. Figure 3 presents a schematic illustration of RUM. The hollow tool can be given a rotary motion as well as it can vibrate. But this makes the design very unwieldy. Hence, an attempt has been made to study the material removal rate when the workpiece is rotated in rotary USM mode. However, owing to the rotation of the workpiece there will be sliding and rolling contacts between the abrasive grains and workpiece, as well 


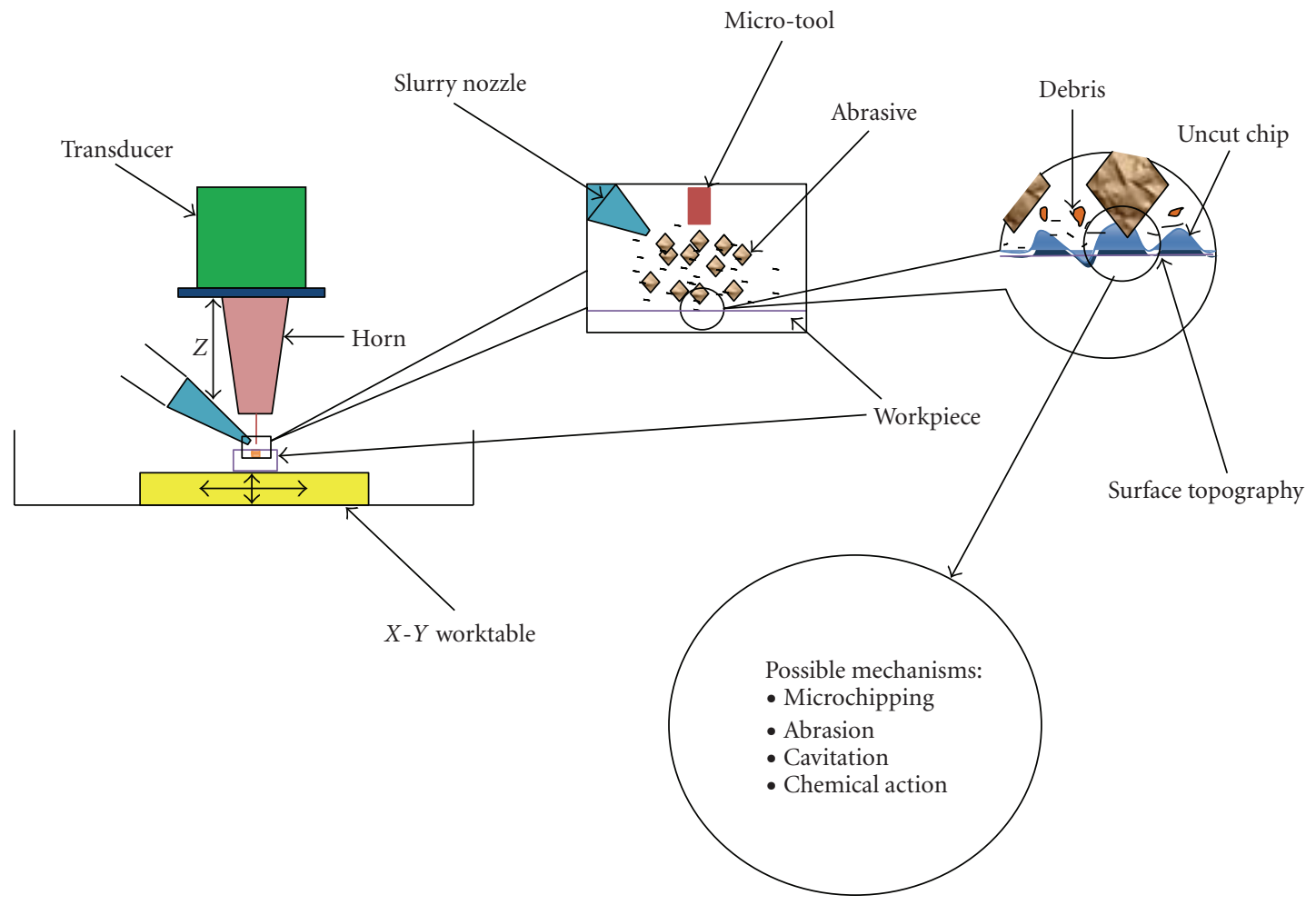

Figure 1: Principles of micro-USM.

as impacts and indentation of the abrasive particle with the workpiece at ultrasonic frequency. Hence better material removal has been claimed [28]. Two major requirements for micro-RUM are the microsized abrasive bonded tool and a machining system capable of applying very small load on the microtool with necessary feedback and control mechanisms.

Some of the disadvantages of the EDM, ECM, and other nonconventional machining processes were overcome by ultrasonic assistance in the form of hybridisation (Figure 2(a)). Thus, ultrasonic machining was combined with EDM and abrasive flow machining (AFM) to achieve better yield [17-19, 29]. Nowadays, ultrasonic vibrations are being used successfully to enhance machining capability of micro-EDM to handle titanium alloys [30]. It has been found in microhole machining of titanium plate that microultrasonic vibration lapping enhances the precision of microholes drilled by micro-electrodischarge machining. Further, USM assisted turning is claimed to reduce machining time, workpiece residual stresses, and strain hardening and improve workpiece surface quality and tool life compared to conventional turning [31].

On the basis of tool head, micro-USM can be divided into two major types: mode I and mode II (Figure 2(b)). Mode I consists of a solid or hollow cylindrical tool which is easy to fabricate and widely used in various applications of micro-USM. Figure 4 illustrates the mode I tool. In mode II, microfeatures are fabricated on the tool bottom. The tool functions as a pattern and is travelled vertically toward workpiece, and, therefore, microfeatures can be "replicated" onto the workpiece in one sinking operation. A unique benefit of this type of micro-USM is to realize a parallel production of many identical simple features. The tool is silver brazed with the tool head and not touching the workpiece. Figure 5 shows the microfeature developed on the tool itself and a gang drill.

In order to minimize tool wear, tools should be constructed from relatively ductile materials such as stainless steel, brass, and mild steel. Curodeau et al. (2008) have proposed an alternative tooling material, in which a viscoelastic thermoplastic composite material is used as tooling to conduct ultrasonic micromachining operations [33]. The proposed tool was successfully investigated for micromachining and micropolishing for tool steel surface.

The machine tools for USM range from small, tabletopsized units to large-capacity machine tools. All USM machines share common subsystems regardless of the physical size or power. The most important of these subsystems are the power supply, transducer, tool holder, tool, and abrasives [35]. In the case of USM transducer, electrical energy is converted into mechanical motion. With a conventional generator system, the tool and horn are set up and mechanically tuned by adjusting their dimensions to achieve resonance. Recently, however, resonance following generators has become available which automatically adjust the output high frequency to match the exact resonance of the horn/tool assembly. They can also accommodate any small error in setup and tool wear, giving minimum acoustic energy loss and very small heat generation. The power supply depends on the size of the transducer. 


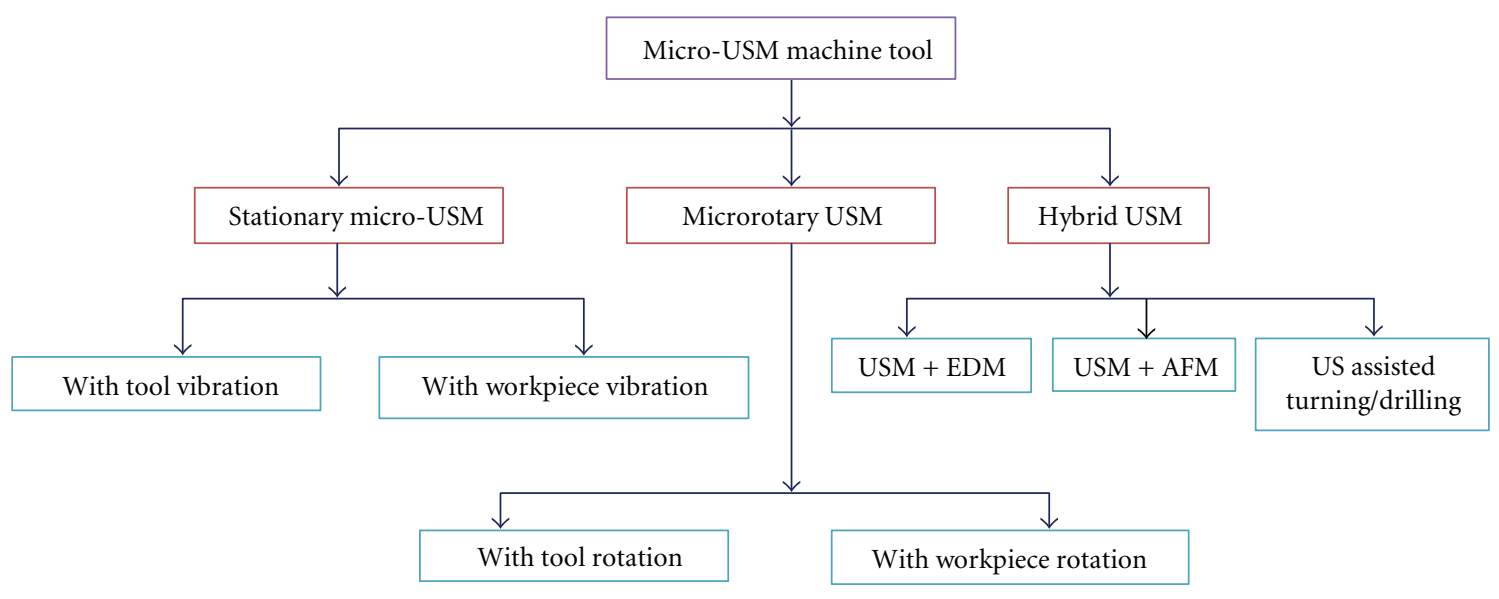

(a)

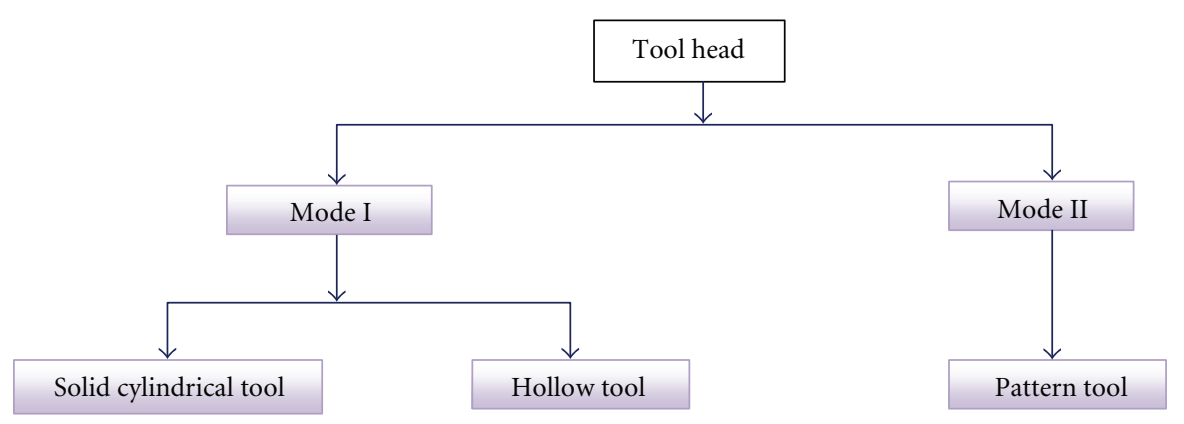

(b)

FIgURE 2: Variants of micro-USM based on (a) machine tool characteristics and (b) different tool heads.

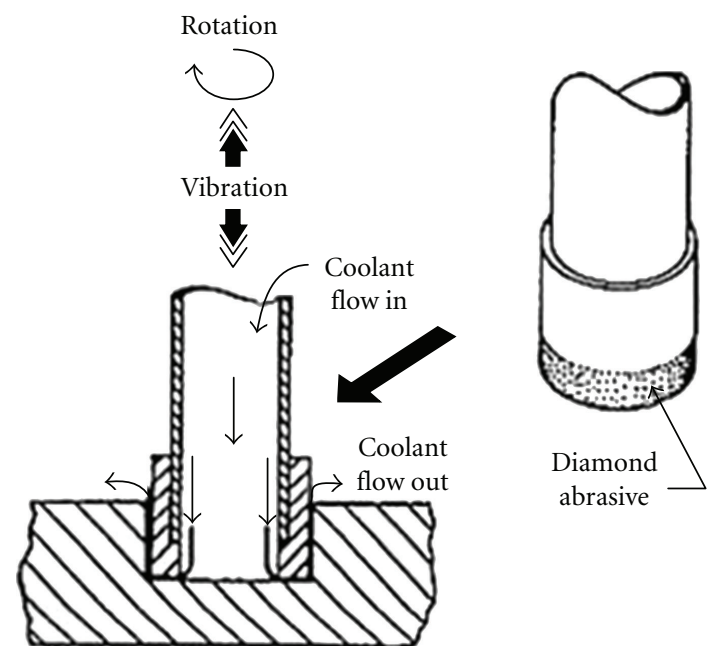

FIGURE 3: Rotary ultrasonic machining process [27].

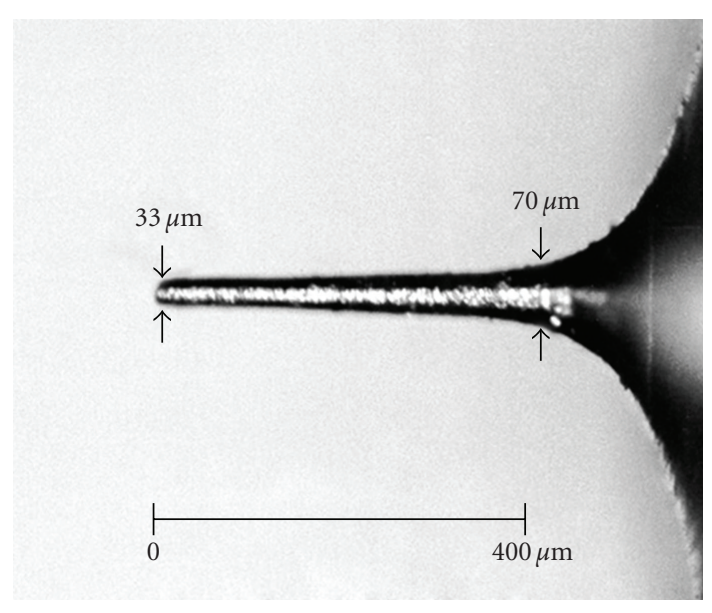

Figure 4: A typical microtool [32].
Two different types of transducers used for USM work on two different principles of operation-piezoelectric and magnetostrictive. Piezoelectric transducers generate mechanical motion through the piezoelectric effect using certain materials such as quartz or lead zirconate. Piezoelectric transducers, by nature, exhibit extremely high electromechanical conversion efficiency (up to 96\%), which eliminates the need for the water-cooling of the transducer. These transducers are available with power capabilities up to $900 \mathrm{~W}$. Magnetostrictive transducers are usually constructed from a laminated stack of nickel or nickel alloy sheets. These types of transducers are rugged but have electromechanical conversion efficiencies ranging from only 20 to $35 \%$ [36]. 


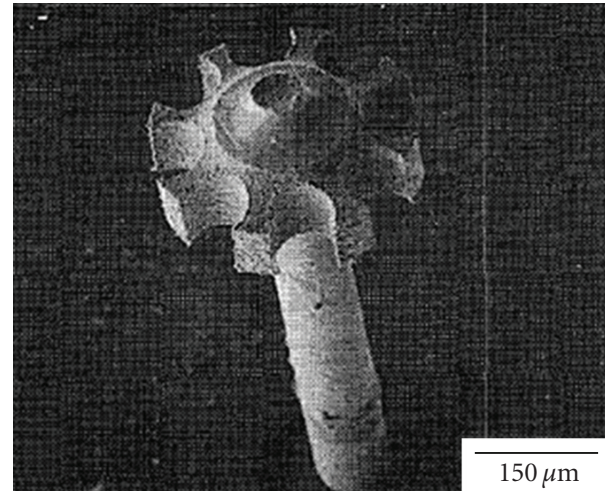

(a)

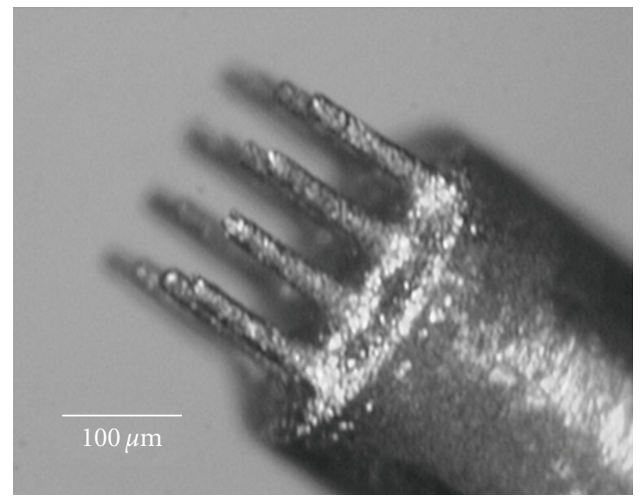

(b)

FIGURE 5: Scanning electron micrograph of a (a) 3D microgear and (b) gang drill produced through microfeatures [22, 34].

\section{Micro-USM Performance Measures}

Extensive research work has been carried out for macroUSM regarding material removal, tool wear, dimensional accuracy, and surface quality [37-39]. However, only a few publications have focussed on the ways of yielding optimal micro-USM performance measures in terms of high material removal rate (MRR), low tool wear rate, and satisfactory surface quality. The main task of process improvement for micro-USM is to economically machine a microfeature with required surface topography, minimal surface damage, good surface finish, high-dimensional accuracy, and acceptable material removal rate. The parametric relationship for micro-USM is complicated due to the involvement of numerous factors and related parameters that could affect the process outputs. The possible parameters in micro-USM can be illustrated in a fishbone diagram as shown in Figure 6.

4.1. Effect of Operating Parameters on Machining Rate. Machining characteristics of micro-USM in the dimension range under $100 \mu \mathrm{m}$ have been first reported and discussed by Egashira et al. [25]. The type and size of abrasive particle affect the machining rate significantly. The machining rate increases with the size of abrasives. The machining speed increases with an increase in the average static load; however, it decreases with the increase of the average static load beyond a certain value. The debris accumulation in the working area leads to a part of the static load consumed in impacting the debris instead of removing the material from the workpiece, resulting in a lower machining efficiency $[40,41]$. The rotation of the tool improves the machining speed significantly as shown in Figure 7. The tool rotation helps in the debris removal and, therefore, increases the machining speed. The drilling speed, however, was reported to be rising with increase in the machining load as that for a single tool does while using cemented carbide tools. In contrast, it decreases as the oscillation amplitude increases [34]. The effects of oscillation amplitude and machining load on drilling speed and tool wear ratio, as reported by Egashira et al. (2004), are illustrated in Figure 8.
4.2. Effect of Operating Parameters on Tool Wear. In USM, the grains hit the tip of the vibrating tool and tend to erode it. Thus, tool wear is an important variable for micro-USM, affecting the machining speed and the hole accuracy. Tool wear tends to increase when harder and coarser abrasive grains are used [25]. When tools of very small dimensions are used, the static load needs to be small to avoid breakage of the tool. A load between 50 to $100 \mathrm{~g}$ for a tool with $65 \mu \mathrm{m}$ diameter or a load of $10 \mathrm{~g}$ for a $20 \mu \mathrm{m}^{2}$ square tool seems to be the best values as reported by Boy et al. (2010) [42]. The populous tool materials such as stainless steel and thoriated tungsten in conventional USM are not suitable in microUSM because of their large wear. Also, tool wear increases remarkably with a decrease in tool diameter $[22,43]$. The tool wear ratio is defined as the ratio of the tool wear length to the hole depth. The tool wear ratio for cemented carbide tools varies widely and is influenced by the machining load or oscillation amplitude as illustrated in Figure 8 [34]. However, larger amplitude than $2 \mu \mathrm{m}$ or a heavier load than $5 \mathrm{mN}$ often results in tool breakage [26].

\subsection{Effect of Tool Geometry on Tool Wear Ratio and Machining} Rate. Some studies on possible effect of tool geometries on machining rate and tool life were also carried out by the present authors. Measurements of machining rate and tool wear ratio as a function of drilling depth were performed using hollow and solid tools. Tools made up of austenitic stainless steel and the hollow tools were having a circular cross section of $500 \mu \mathrm{m}$ outside diameter and $450 \mu \mathrm{m}$ inside diameter. The silicon wafers with $500 \mu \mathrm{m}$ thickness were employed as workpiece material for the drilling trials. The experiments were carried out in a stationary Sonic-Mill machine (AP-500) with a power output of 500 W. A 20\% power rating was used during the experiments. The static load applied on the horn was taken in the range of $100 \mathrm{~g}$ to $300 \mathrm{~g}$ throughout the trials.

Figure 9 illustrates the variations in the observed machining rate (MR) as a function of the static load for the two types of tool. In both types of tool used, the overall machining rate increases with an increase in the static load. 


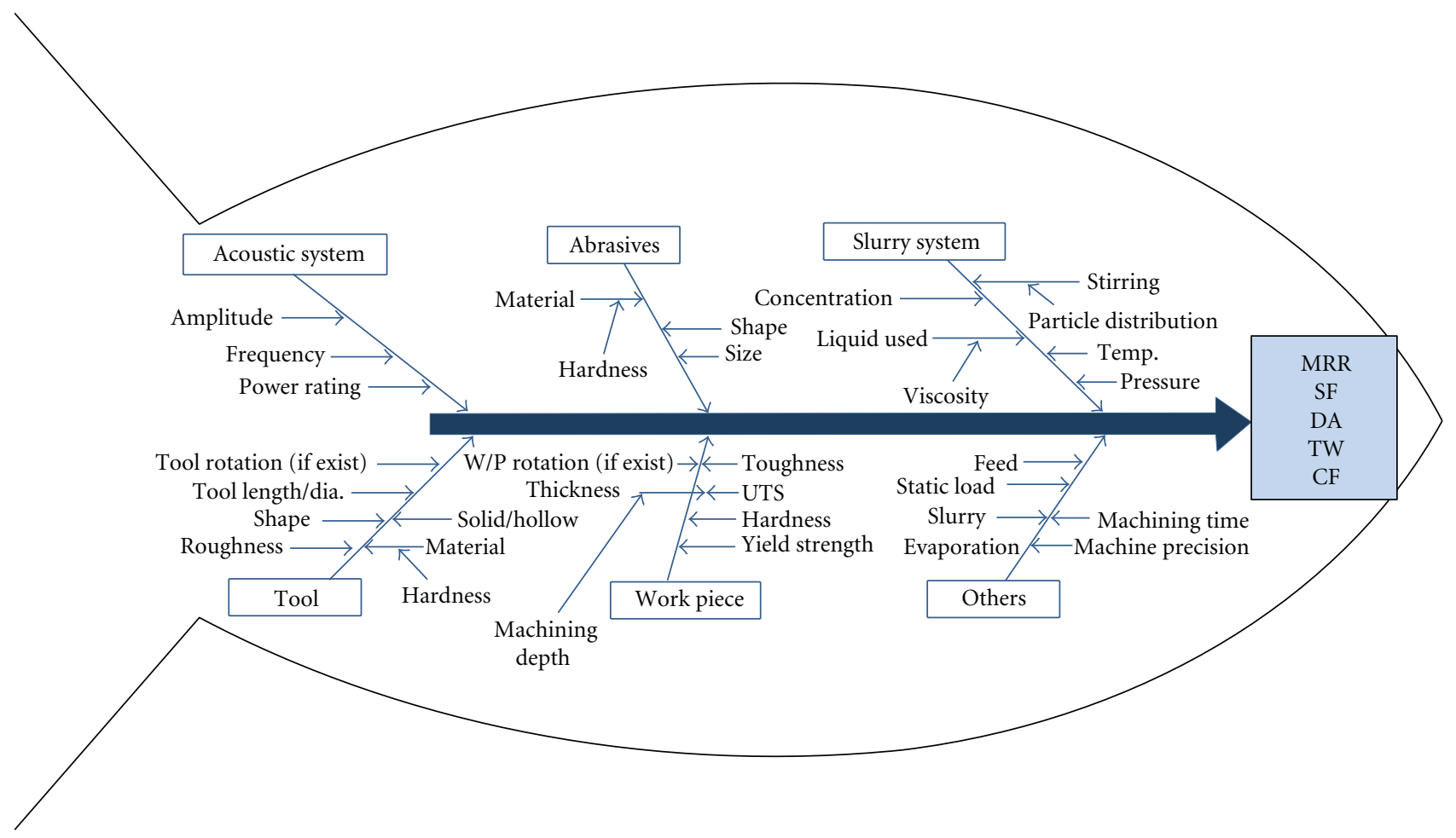

MRR: material removal rate

SF: surface finish

DA: dimensional accuracy

TW: tool wear

CF: cutting forces

FIGURE 6: Subsystems and associated parameters in micro-USM.

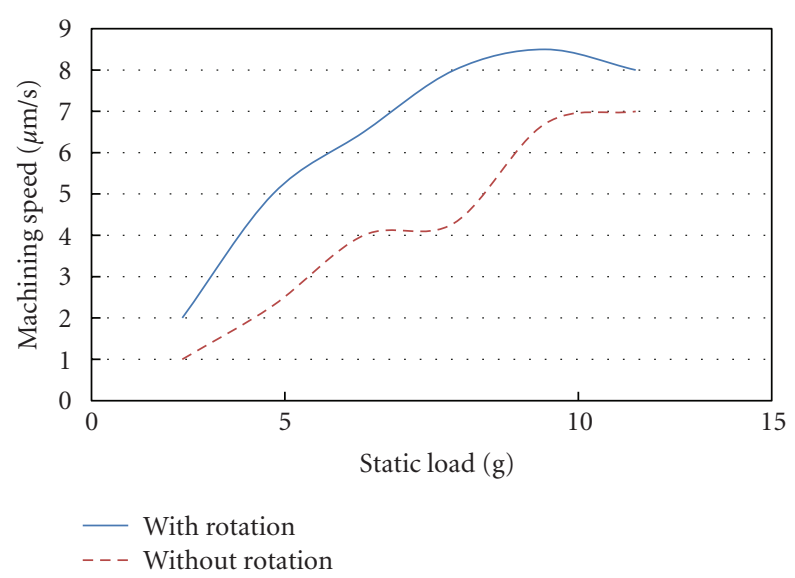

Figure 7: Machining speed as a function of average static load (based on data [40]).

Increase in static load means increasing the pressure on the abrasive grains and eventually on the workpiece, resulting in an increase of machining rate. However, the machining

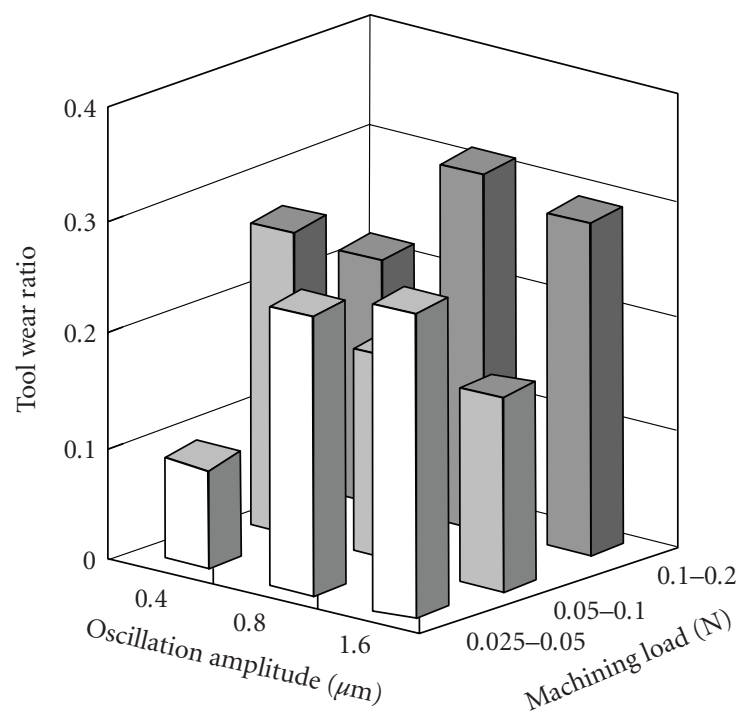

Figure 8: Tool wear ratio for cemented carbide tool [34].

rate decreases with the increase in static load differently for the two types of tool. Decrease in MR with increasing static load is explained by the insufficiency in recycling abrasive 


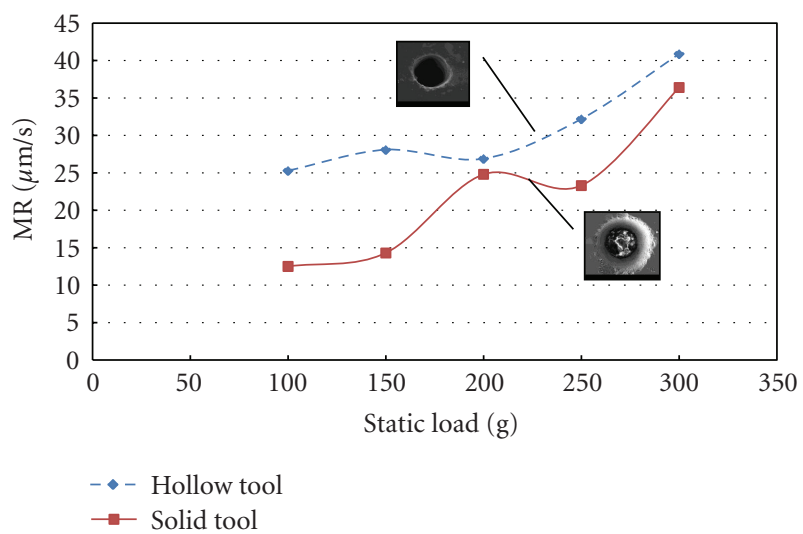

FIgURE 9: Variation of machining rate as a function of static load; insets: SEM micrographs of ultrasonically machined surfaces of silicon with hollow tool and solid tool.

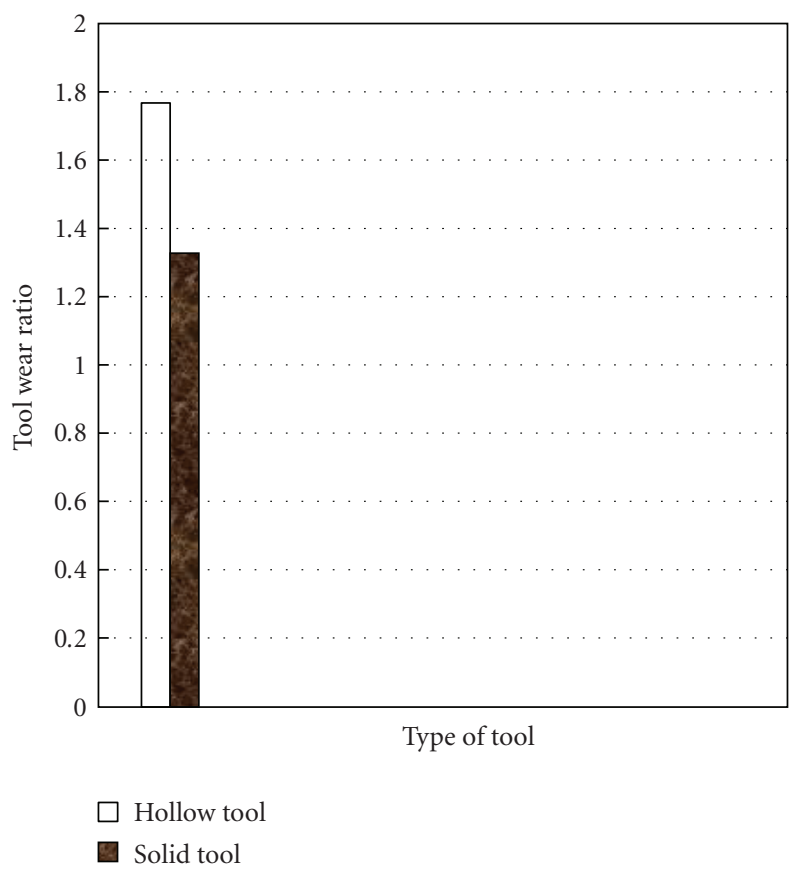

FIGURE 10: Tool wear ratio of different tool.

particles at the machining interface because of accumulation of the debris. The recycling capacity affects the hammering and impact actions of the abrasive particles in the working gap. Also, the MR is more in case of hollow tool with the varying static load. This is because of the necessary contact area between the tool and abrasives and correspondingly between abrasives and the workpiece. In case of hollow tool, material is removed by the border of the tool only whereas in case of a solid tool, the whole lower edge is involved in machining. The design of a tool must be such that it should machine as little of the workpiece material as necessary. The importance of tool head area can also be seen from the accompanying scanning electron micrograph (SEM) images in Figure 9. Higher straying abrasive action is seen with the solid tool, while the hollow tool provides a more focused cutting zone, although at the cost of higher tool wear. Thus, further studies in this direction would be needed to obtain optimal machining conditions.

Figure 10 illustrates the tool wear ratio of different types of tool used. The observed higher tool wear ratio in case of hollow tool is attributed to reduced contact area. As the contact area is less for a constant load, the stress produced will be more which results in easy and quick work hardening of the tool tip. This leads to an induced brittleness on the tool tip causing a favourable condition to be eroded by the deflected abrasives. In addition, the problem of debris accumulation also causes the crack generation and material removal from the tool, leading to the more tool wear.

4.4. Effect of Operating Parameters on Surface Finish. The type and size of abrasive particle affect the surface finish and it increases as the size of abrasive increases. Egashira et al. have reported that tungsten carbide (WC) causes the worst surface as compared to titanium carbide (TiC) [25]. Theoretically, the surface roughness is small when small particles are used because of the small crater generated. However, because of debris accumulation, the surface roughness generated by small abrasive particles can be larger than that of big particles. If abrasive particles of small size are used, particles get embedded in the workpiece or in the tool under the static load and may stay in their original craters without moving to other locations during several cycles of vibration. The thickness of accumulated debris in the working area reaches the exposed height of abrasive particles in a short time, resulting in the debris involved in machining. This leads to a change in the abrasive particle distribution and movement, which may increase the surface roughness. When large abrasive particles are used, more debris is removed from working area and the abrasive particles easily move to new locations by the vibration because of the large number of impacts $[40,41]$. Surface roughness, out-of-roundness and taper ratio are three important parameters for evaluating microhole quality $[22,43]$. Cutting forces are reduced by 60 to $70 \%$ with ultrasonic vibrations which result in increase in tool life, penetration, and tool length, thereby improving surface finish, and machinable depth [44]. Rotating the tool not only decreases the severity of protrusions along the machining path, but also improves machining speed as observed by Kuriyagawa et al. (2001) [32].

\section{Geometrical Capabilities}

The geometrical capabilities of micro-USM have been verified by machining microfeatures such as blind or through holes, slots, and 3D cavities. Ultrasonic machining has a limitation in its application to micromachining because there are problems in fixing microtools to the machine and maintaining high precision. Accordingly, a technique was proposed for micro-USM by applying on-the-machine tool fabrication by wire electrodischarge grinding (WEDG). As a result, microholes as small as $20 \mu \mathrm{m}$ in diameter and $50 \mu \mathrm{m}$ depth on a silicon plate, and quartz could be made. Figure 11 


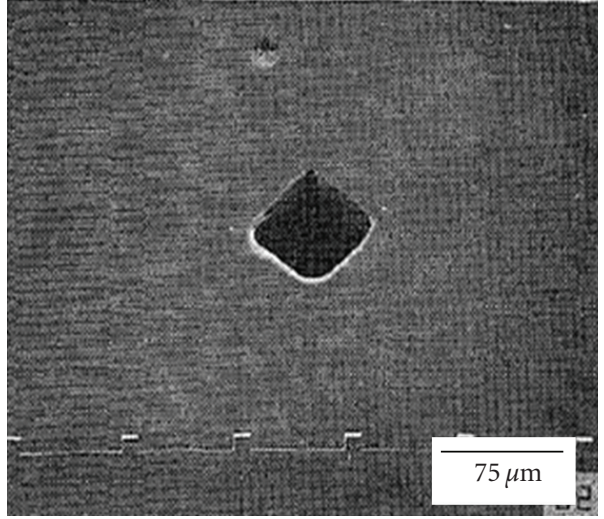

(a)

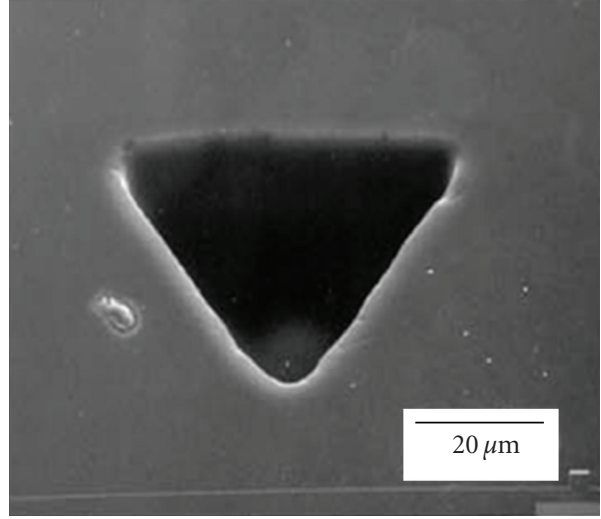

(b)

FIgURE 11: Square and triangular holes on silicon [25].

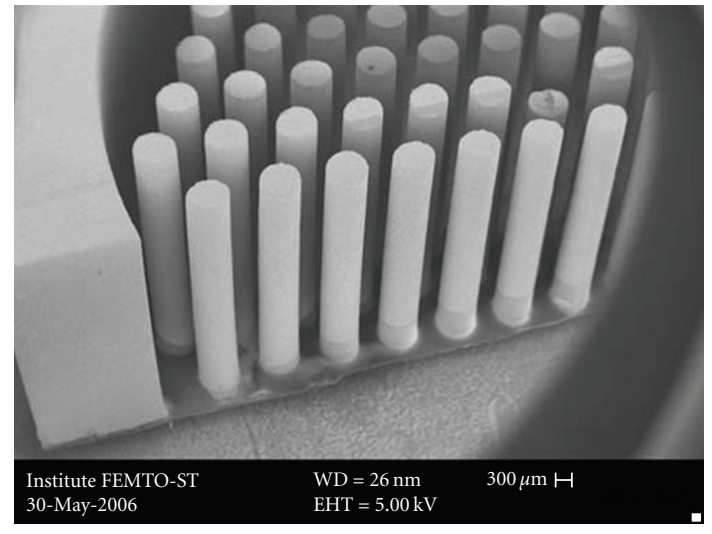

FIgURE 12: Typical ultrasonically machined structure [42].

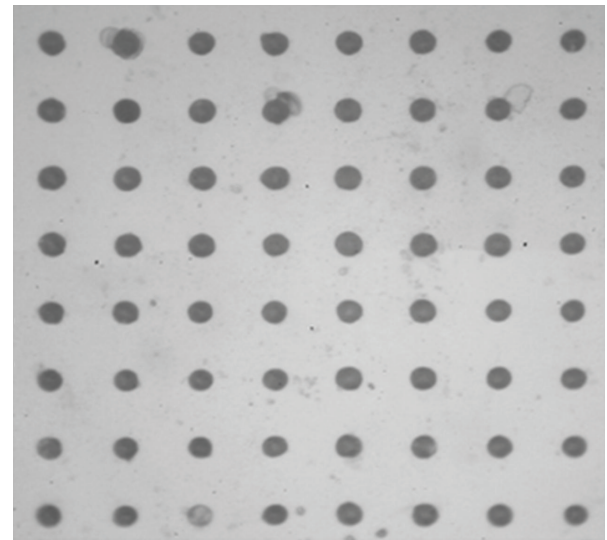

Figure 14: Microholes $20 \mu \mathrm{m}$ in diameter [34].

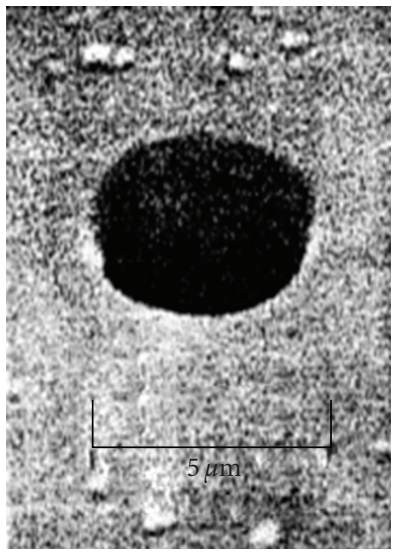

(a)

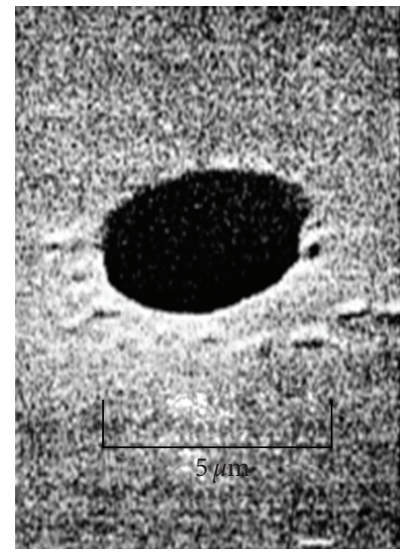

(b)
Figure 13: Microholes in silicon and glass $[25,26]$.

shows a triangular and square hole made on silicon using WEDG method, as reported by Egashira et al. (1997) [25].

A machine was developed at FEMTO-ST institute, France for producing electronic components based on piezoelectric quartz crystals for ultraprecise processing on 2-in. wafer. Through holes of high quality were easily produced; blind holes were also machined with a depth accuracy within $10 \mu \mathrm{m}$. Figure 12 illustrates arrays of pillars of $280 \mu \mathrm{m}$ diameter and $6,000 \mu \mathrm{m}$ depth in Lead Zirconate Titanate (PZT), which were produced using a steel disk with an array of $300 \mu \mathrm{m}$ diameter holes (honeycomb structure) [42]. A hole of $15 \mu \mathrm{m}$ in diameter but only $32 \mu \mathrm{m}$ depth has been achieved by Sun et al. [22]. An array of microholes were drilled in micro-USM using a cemented carbide multitool having diameter $18 \mu \mathrm{m}$ as shown in Figure 5(b). The drilling was performed four times and a total of 64 holes could be fabricated with an oscillation amplitude of $0.8 \mu \mathrm{m}$ and a machining load of 0.05 to $0.1 \mathrm{~N}$. The workpiece material was soda lime glass. In an extreme attempt, micro-USM was used to drill microholes of diameter $5 \mu \mathrm{m}$ in silicon and soda lime glass as shown in Figure 13.

The major efforts to improve the micro-USM process performance are to increase its throughput by using novel microtooling technology, especially for Mode II micro-USM (Figure 2(b)). Micro-USM with a single tool had so far been carried out on hard and brittle materials; however, it is 


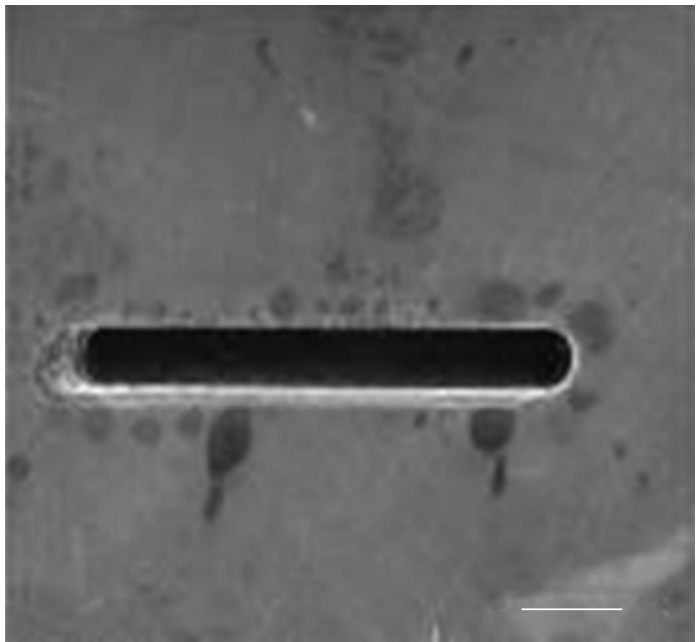

(a)

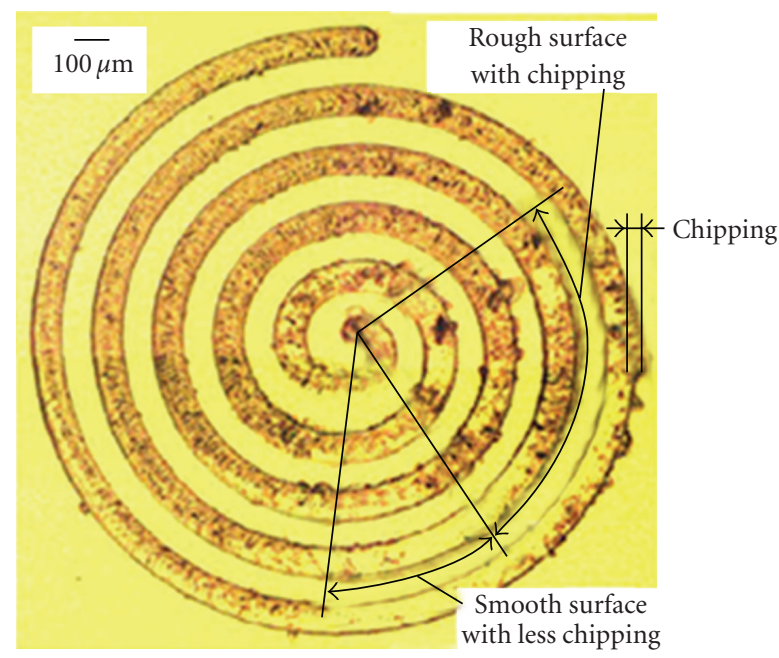

(b)

FIGURE 15: (a) Straight microslot, (b) Spiral groove [22].

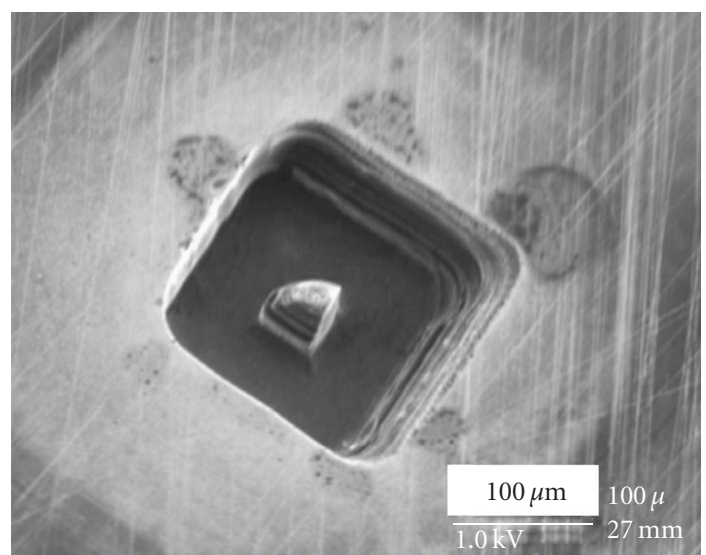

FIGURE 16: A typical 3D cavity [41].

time-consuming for drilling multiple holes, which is often a requirement for application of microholes. Thus, a microEDM has been used to drill parallel holes, which is later used to produce microcemented carbide multitool using reverse micro-EDM. The multitool is further used in mode II microUSM. The fabricated multitool (Figure 5) and the array of microholes machined by micro-USM are shown in Figure 14.

A fabrication process combining lithography, electroplating, batch mode micro-electrodischarge machining ( $\mu \mathrm{EDM})$ and batch mode micro-USM, LEEDUS, was developed by $\mathrm{Li}$ and Gianchandani (2005) to provide die-scale pattern transfer capability from lithographic masks onto ceramics, glass, or other brittle materials. A die (eventually a wafer) with electroplated metal structures (the desired pattern needs to be present in the final machined part) was used as a micro-EDM electrode. The die-scale (or wafer-scale) negative pattern is transferred onto the tool material during

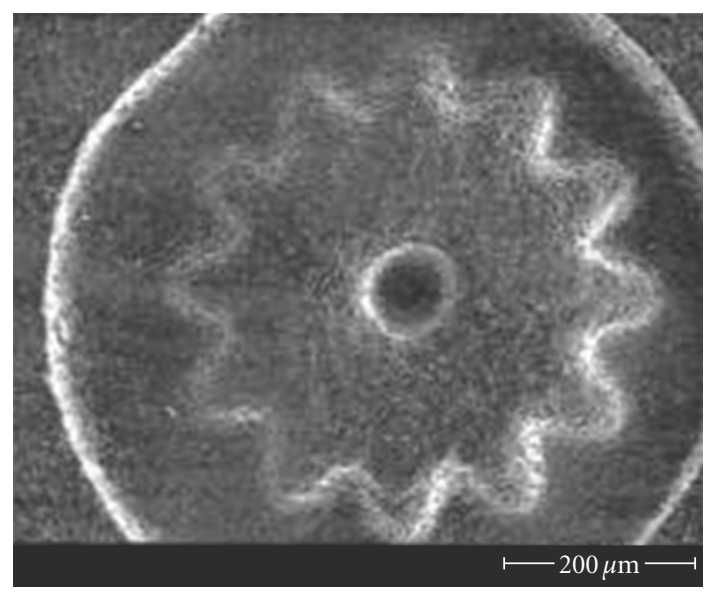

Figure 17: Die-sinking Micro-USMed feature in Alumina [45].

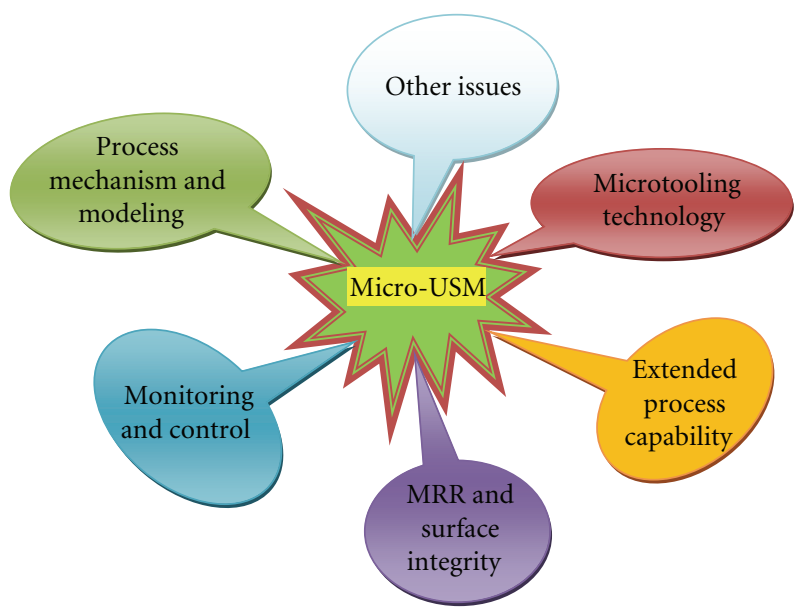

FIgURE 18: Major research issues in micro-USM. 


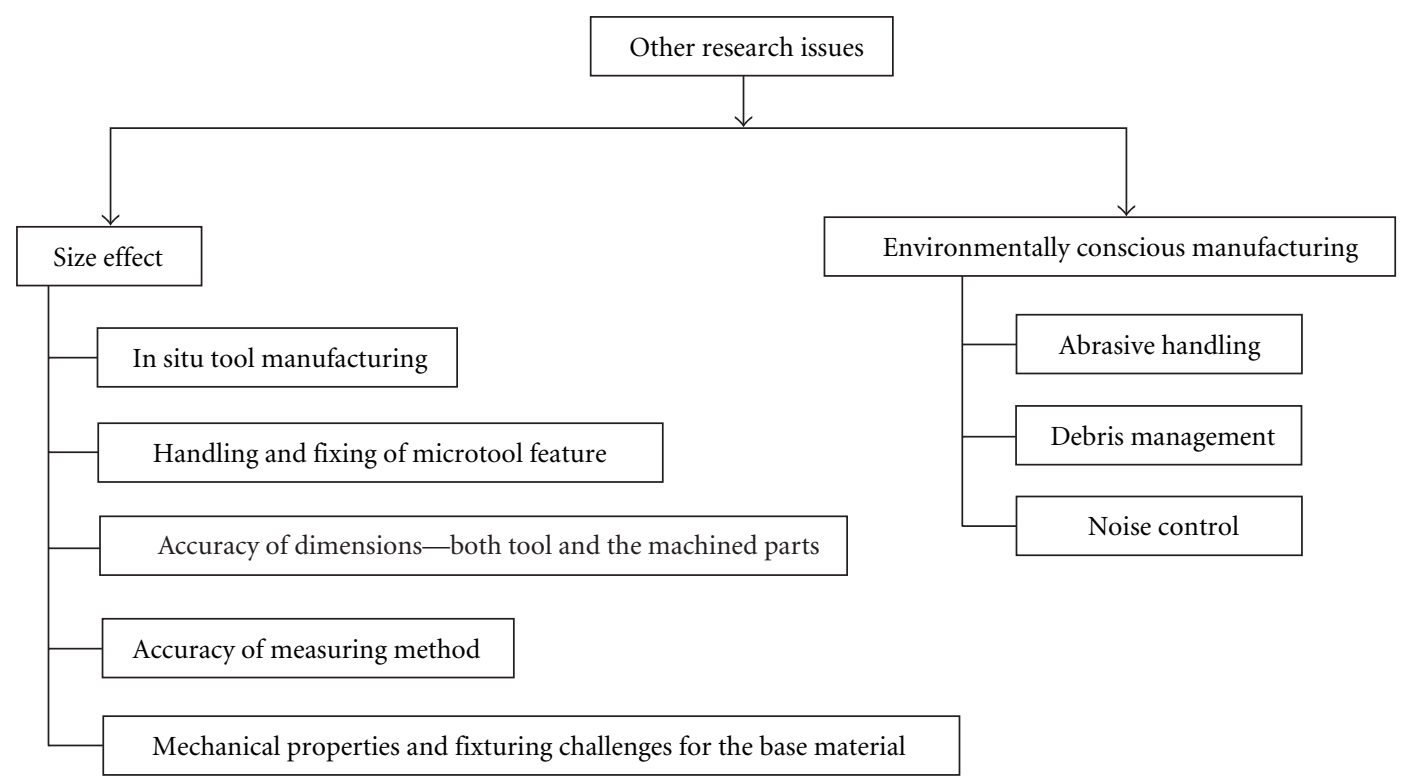

FIGURE 19: Size effect and environment dominant research paradigms.

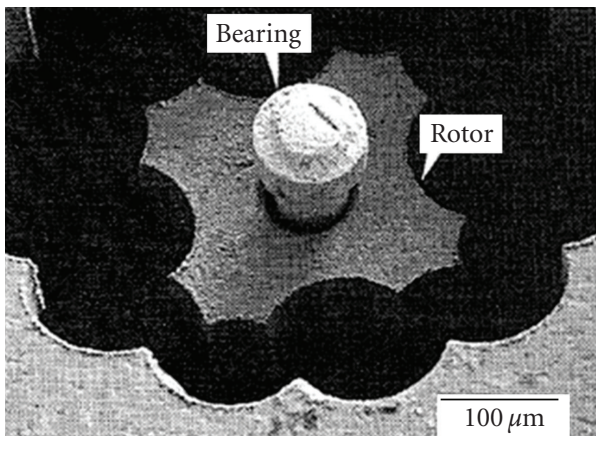

(a)

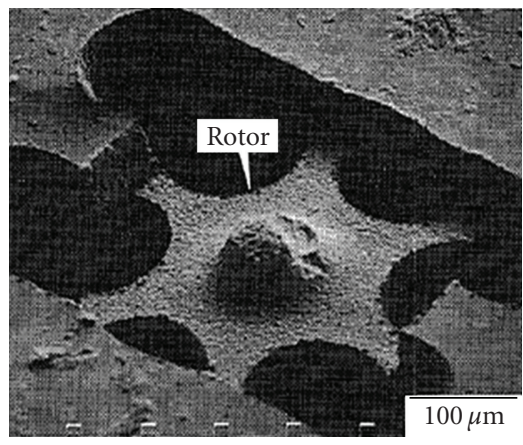

(b)

Figure 20: (a) Centre-pin bearing airturbine and (b) Micro force-balance airturbine [22].

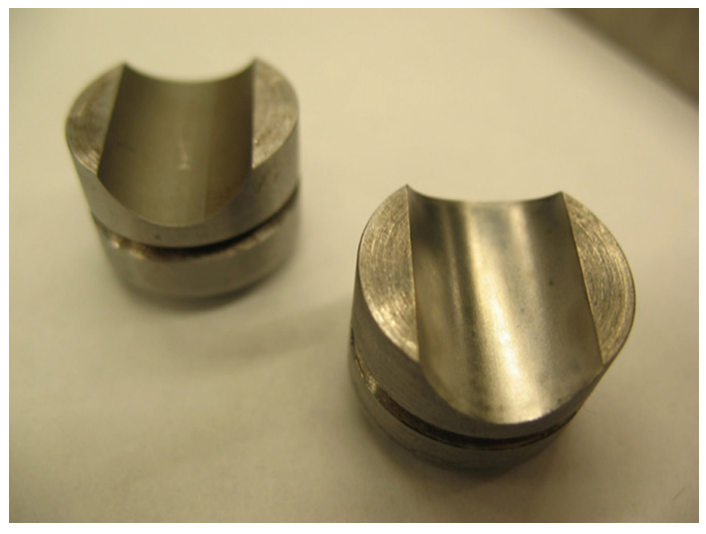

FIGURE 21: A micropolished tool steel surface [33].

micro-EDM, and then the positive pattern is transferred onto the workpiece by mode II Micro-USM [46].

Figure 15(a) shows a straight slot (width $47 \mu \mathrm{m}$, length $500 \mu \mathrm{m}$, and depth $60 \mu \mathrm{m})$ with vertical side wall being machined by Sun et al. (1996) using a layer-by-layer contouring mode through micro-USM system. Furthermore, contouring mode micro-USM was illustrated by generating a spiral groove on low-melting glass as shown in Figure 15(b) [22].

A complex-shaped microfeature can be generated by moving the microcylindrical tool along with a designated tool path. An arbitrary 3D micro cavity was successfully machined on silicon using a cylindrical-shaped microtungsten tool by Yu et al. (2004) as shown in Figure 16 [41]. During machining, the microtool was driven in all three axes to follow a designed tool path created by CAD/CAM method. To compensate the large tool wear, the "Uniform Wear Method", which was originally developed for producing 3D features in micro-EDM, was applied to postprocess a tool path generated by CAD/CAM system. Tool shape was maintained by specifying layer-by-layer machining.

Figure 17 shows a feature machined on alumina, considered to be an important step in realizing mode II microUSM for pattern transfer in fabricating complex shaped tool. 


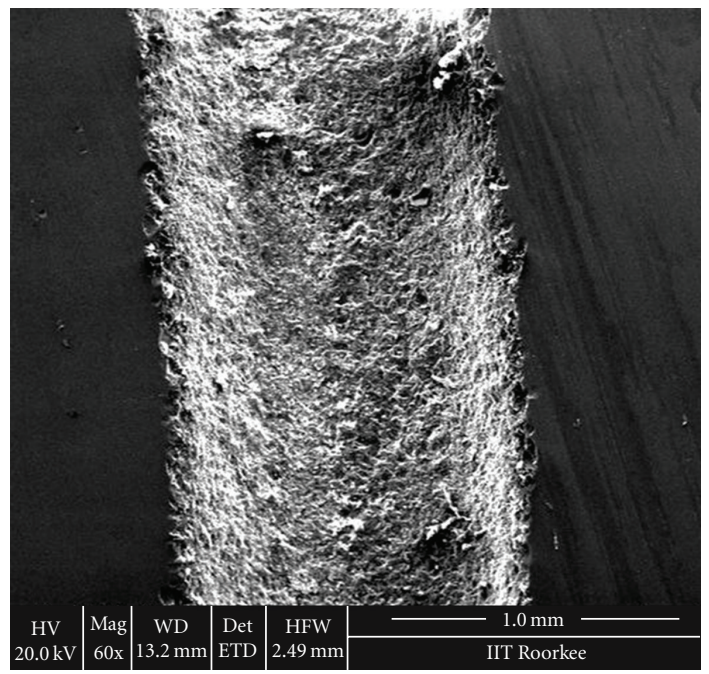

(a)

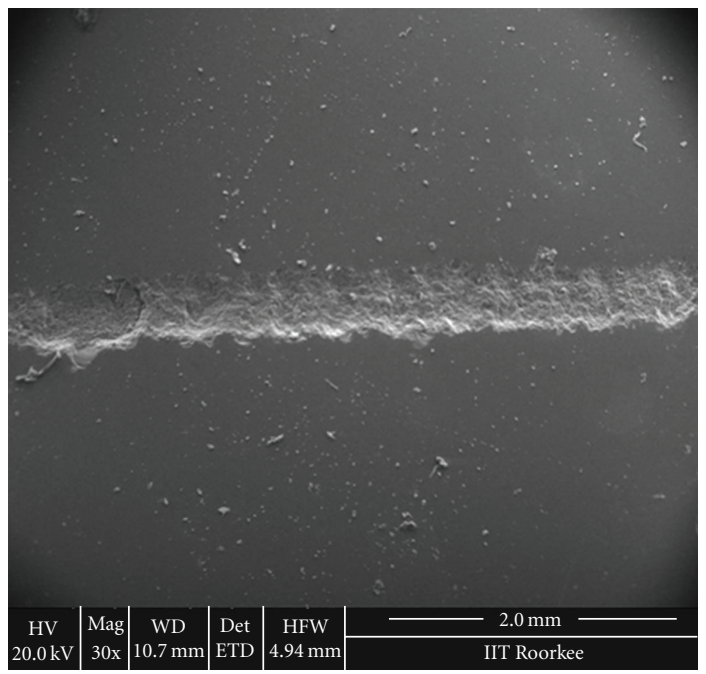

(b)

FIGURE 22: Microchannels machined using micro-USM on (a) glass and (b) silicon.

TABLE 3: Micro-USM process capabilities.

\begin{tabular}{llll}
\hline Sr. no. & Features & Capability & Reported by \\
\hline (1) & $\begin{array}{l}\text { Minimum } \\
\text { diameter, } \mu \mathrm{m}\end{array}$ & 5 & $\begin{array}{l}\text { Egashira et al. } \\
(1997)[25]\end{array}$ \\
& $\begin{array}{l}\text { Maximum } \\
\text { (Depth } \times\end{array}$ & $60 \mu \mathrm{m} \times 500 \mu \mathrm{m}$ & $\begin{array}{l}\text { Sun et al. (1996) } \\
{[22]}\end{array}$ \\
& $\begin{array}{l}\text { Length), } \mu \mathrm{m} \\
\text { Max. no. of } \\
\text { (3) }\end{array}$ & $\begin{array}{l}16 \text { microtools of } \\
\text { features on single } \\
\text { tool }\end{array}$ & $\begin{array}{l}\text { Egashira et al. } \\
(2004)[34]\end{array}$ \\
& & $\begin{array}{l}\text { Array of pillars } \\
(280 \mu \mathrm{m} \text { diameter }\end{array}$ & $\begin{array}{l}\text { Boy et al. (2010) } \\
\text { [42] }\end{array}$ \\
& Others & and $6000 \mu \mathrm{m}$ depth) & \\
\hline
\end{tabular}

Such fabrication is obviously more difficult than producing simple cylindrical tool. The newly developed microultrasonic assisted lapping technique shows flexible capability in generating microstructures of various geometrical forms [45]. Major micro-USM process capabilities can be summarised in Table 3. However, there are many technical constraints to be overcome like the achievable concave feature size, aspect ratio, and surface roughness limits, as well as an operational issue incurred by tool wear. A focussed discussion on process capabilities of the micro-USM process was also presented by Hu et al. (2006) elsewhere [47].

\section{Research Issues}

In experimental investigations, micro-USM has been recognized as a promising micromachining process for generating microscale features in (nonconducting) brittle and hard materials. However, research works on micro-USM so far are mainly focused on exploring the feasibility and geometrical ability of machining. One of the possible reasons is that to a certain extent some aspects of micro-USM are similar to macro-USM and can be directly implemented. However, issues with micro-USM need not be similar to that of macroUSM. Few such issues associated with surface finish and removal of debris have already been discussed in Section 4.1. Further, it is quite possible that mechanism of material might get influenced by other factors usually not considered important in macro-USM. Various research issues in the micro-USM process can be categorised as illustrated in Figure 18. Most of these issues are concerning the major task of process improvement for micro-USM.

Interactions between abrasive particles and workpiece are very intricate in micro-USM. A well-structured study for understanding of the material removal mechanism for micro-USM is yet to be carried out. Further analysis of the material removal mechanism associated with the machining process is required. The contribution of each probable phenomenon that might be active during the removal of material including microchipping, abrasion, cavitation, and chemical reaction needs to be investigated. In a microcutting situation, localised temperature might play a significant role too, which call for further research.

The process output parameters (such as material removal rate and surface roughness) of micro-USM depend mainly on the physical/mechanical phenomena at the machining gap. In such processes, many research issues can be originated from the practical requirements (such as surface finish) and existing limitations (such as serious tool wear, particle size, and surface finish) of the process. Studies on process capabilities and process modelling are few aspects that can contribute immensely towards making the process cost effective. Microtooling is another aspect which could contribute significantly towards process capability and such issues need to be addressed early.

Further, although ample process monitoring and control strategies are already in use, the issues might need be relooked in the context of noise reduction and high 
frequency-low amplitude requirements of the process with adaptive control option owing to finer movements associated.

Other issues can also be summarized as in Figure 19.

Micromachining is not merely reduction in size of the machining conditions such as tool size, abrasive size, vibration amplitude, and feature size. There are other inherent difficulties which should be addressed and treated as research issues. These issues can further be broadly categorised into what is termed as "size effects" and "environmentally conscious manufacturing". There are a number of issues associated with each broad category and can be detailed as illustrated in Figure 19. The size effects include problems like preparation of microtools, their handling, and fixing of the tool feature to the tool holder. The accuracy and performance of micromachining processes depend on the accuracy and appropriateness of the microtool also. However, preparation and physical attachments of such tools are big challenges faced by the micromachining industries. Efficient and accurate methods to develop microtools will significantly influence the processing time, processing quality, and hence the production economy. Focussed researches in this direction can help overcoming such issues. The alignment of the tool plays a vital role and must be accurate to confirm the accuracy of machining. Making a tool with a traditional method (micromilling) and then fixing it with silver brazing or soft soldering to the tool holder does not validate its alignment because the tool is too small for traditional machining and assembling methods. Hence, suitable methods which are capable to fabricate the microtool on the machine itself and maintain the high precision need to be developed. Egashira et al. (1997) have proposed some solutions in the last decade itself and fresh investigations would result further improvements [25].

Another issue included in the size effect is accuracy of dimensions and its measurement methods. Considering the feature size in use (usually, smaller than $500 \mu \mathrm{m}$ ), it is desirable that the measuring equipments are of sufficiently higher. Calibration of such equipment and handling of the micromachined parts for measurements are also challenging. Therefore, in situ microtool preparation and in situ product inspection systems need to be developed in order to minimize the production error and ensure product quality.

The mechanical properties of workpiece material, related handling, and holding difficulties onto the micromachining facility are some other issues that need to be addressed. Multipurpose automatic holding and positioning devices with requisite accuracies need to be developed which will reduce the idle time significantly. The work material used for micromachining is generally very brittle; therefore, proper method of workpiece mounting and controlling of tool is essential to avoid probable damage of the workpiece.

One of the important issues which has hardly been addressed is the environmental aspects. It is one of the requirements of modern manufacturing that the material processing techniques be environment friendly. The noise produced by the ultrasonic frequency generating system itself can be a concern for the human beings in the range. The micro-USM process involves fine abrasives which are certainly not safe for human being to consume. The normally used abrasives (boron carbide, silicon carbide, etc.), although not very well known for their toxicity like the reactants used in the chemical-based processes, can however, cause health hazards during handling. The microchips generated during the process get mixed with the slurry. The efficiency of the process decreases as the debris-mixed slurry is recirculated. Thus, the recirculated slurry contains work material constituents apart from the chemically passive abrasives. Safe handling of this abrasive slurry makes the process more complex. Appropriate methods for separation and/or safe disposal need to be developed to make the process more environment friendly. This debris accumulation in the micromachining zone also results in low MRR and affects dimensional accuracy. Hence, proper debris separation and management method needs to be developed in order to enhance the process efficiency and make the process more environmentally acceptable.

The process capability of micro-USM can further be extended by exploring its application in the area of fabrication of components used in microfluidics. It can be attempted to machine microchannels on glass and silicon for micro-heat exchanger applications and for microsensors. The micro-USM technique has not been so far applied for making of microchannels and can be a topic of research.

\section{Potential Applications}

Potential applications of micro-USM with rotated tool include the production of high-aspect-ratio microholes (less than $100 \mu \mathrm{m}$ in diameter) in silicon and glass wafers, which are in great demand for pressure and flow sensors [43]. Various specific applications include drilling small holes in helicopter power transmission shafts and gears, machining of watch bearings and jewels, slicing semiconductor components, for example, cutting circular wafers and drilling small holes in borosilicate glass. Self-aligned multilayer machining and assembly (SAMMA) is a combined machining and assembly method, which specifies that the machining and the assembly of microparts are fulfilled on the same machine without separate processes. Two 3D microair turbines made up of three layers have been developed using SAMMA and micro-USM [22] and are shown in Figures 20(a) and 20(b). Ultrasonic micromachining can also be efficiently used to micromachine as well as micropolish a tool steel surface with a thermoplastic tool as shown in Figure 21. The micro-USM process can be of extremely useful for the semiconductor industry as the industry needs processing of characteristically brittle materials. The applications of the process can also be explored for processing metal-based materials relatively ductile with suitable adaptations which can be of high demand in microfluidics and heat transfer applications.

With the increased awareness of microfluidic physics and the surface science of silicon, polymers, glass, and ceramics, these newer and harder work materials are strongly recommended for the micro-electromechanical system (MEMS). All of these microfluidic systems require the use of micron-sized channels and cavities for liquid or gas 
delivery and storage. Especially, microchannels and their fabrication technologies are playing an important role in the current development of bio-MEMS. Recently, the present authors have successfully used micro-USM to fabricate such microchannels on glass and silicon as shown in Figures 22(a) and 22(b), respectively. These channels were fabricated using a conventional USM (Sonic Mill) at $20 \mathrm{kHz}$ with silicon carbide abrasives of $20 \mu \mathrm{m}$ size. Austenitic stainless steel tool heads were used for the trials. The finish of the machined surface will be enhanced considerably with the use of finer abrasives; the currently used $20 \mu \mathrm{m}$ abrasives appear too coarse.

\section{Conclusion}

This paper provides an overview of the main issues concerning different aspects of micro-USM, its performance, and limitations in the application. The paper focuses on the principle of micro-USM, the types of USM processes, tooling, USM process parameters, and the process performance measures, namely, material removal rate and the tool wear ratio. Categorisations of micro-USM processes according to the operating principles used and tool head used have been presented. Mechanics of material removal with reference to the vis-á-vis macro-USM has been illustrated. A comparison with respect to major features of the widely used micromachining processes has been presented. Geometrical capabilities of the micro-USM process have been explored on the basis of reported literature. The presented results can help to plan the process within the expected tolerances. The following major conclusions may be drawn from the present study.

(i) Microultrasonic machining (micro-USM) is derived from macro-USM, which has been a well-established industrial process offering attractive capabilities to machine hard and brittle materials.

(ii) The contributing mechanisms involved in microUSM, as in macro-USM, are micro chipping by impact of the free moving abrasive particles, mechanical abrasion by the abrasive particles against the workpiece surface, cavitation effects in liquid agitated by ultrasonic vibration, and chemical actions associated with the liquid being employed.

(iii) The design of tool and transducer capacity plays an important role in providing a resonance state in USM to maximize the material removal rate.

(iv) The hardness of abrasives material should be more than the workpiece as in case of macro-USM. In general, larger abrasive grit sizes and higher slurry concentrations result in higher MRR.

(v) In micro-USM, finer particles might cause deterioration to the surfaces owing to getting pushed into the eroded cavities and inefficient flushing. This is contrary to the general understanding of using finer abrasives for finer surface finish. (vi) Providing ultrasonic vibrations to the workpiece material while carrying out micro-USM appears more effective contrary to the conventional USM.

\section{References}

[1] T. Masuzawa, "State of the art of micromachining," CIRP Annals-Manufacturing Technology, vol. 49, no. 2, pp. 473488, 2000.

[2] E. Gentili, L. Tabaglio, and F. Aggogeri, "Review on micromachining techniques," in Proceedings of the 7th International Conference on Advance Manufacturing Systems and Technology (AMST'05).

[3] J. J. Allen, Micro Electro Mechanical System Design, CRC Press, Boca Raton, Fla, USA; Taylor \& Francis, London, UK, 2005.

[4] R. T. Howe and R. S. Muller, "Polycrystalline silicon micromechanical beams," Journal of the Electrochemical Society, vol. 130, no. 6, pp. 1420-1423, 1983.

[5] E. W. Becker, W. Ehrfeld, P. Hagmann, A. Maner, and D. Münchmeyer, "Fabrication of microstructures with high aspect ratios and great structural heights by synchrotron radiation lithography, galvanoforming, and plastic moulding (LIGA process)," Microelectronic Engineering, vol. 4, no. 1, pp. 35-56, 1986.

[6] P. J. French, P. T. J. Gennissen, and P. M. Sarro, "New silicon micromachining techniques for microsystems," Sensors and Actuators, A, vol. 62, no. 1-3, pp. 652-662, 1997.

[7] F. Z. Fang, K. Liu, T. R. Kurfess, and G. C. Lim, "Tool-based micro machining and applications," in MEMS, MEMS/NEMS, Handbook Techniques and Applications, vol. 3, Springer, Berlin, Germany, 2005.

[8] J. L. Liow, "Mechanical micromachining: a sustainable microdevice manufacturing approach?" Journal of Cleaner Production, vol. 17, no. 7, pp. 662-667, 2009.

[9] C. K. Walker, G. Narayanan, H. Knoepfle et al., "Laser micromachining of silicon: a new technique for fabricating high quality terahertz waveguide components," in Proceedings of the 8th international symposium on Space Terahertz Technology, Harvard University, March 1997.

[10] A. A. Tseng, Y. T. Chen, C. L. Chao, K. J. Ma, and T. P. Chen, "Recent developments on microablation of glass materials using excimer lasers," Optics and Lasers in Engineering, vol. 45, no. 10, pp. 975-992, 2007.

[11] J. P. Desbiens and P. Masson, "ArF excimer laser micromachining of Pyrex, SiC and PZT for rapid prototyping of MEMS components," Sensors and Actuators, A, vol. 136, no. 2, pp. 554-563, 2007.

[12] Z. Y. Yu, K. P. Rajurkar, and H. Shen, "High aspect ratio and complex shaped blind micro holes by micro EDM," CIRP Annals-Manufacturing Technology, vol. 51, no. 1, pp. 359362, 2002.

[13] S. Mahendran, R. Devarajan, T. Nagarajan, and A. Majdi, "A Review of Micro-EDM," in Proceedings of the International Multi Conference of Engineers and Computer Scientists, vol. 2, Hong Kong, March 2010.

[14] B. Bhattacharyya, M. Malapati, and J. Munda, "Experimental study on electrochemical micromachining," Journal of Materials Processing Technology, vol. 169, no. 3, pp. 485-492, 2005.

[15] R. Singh, M. J. Alberts, and S. N. Melkote, "Characterization and prediction of the heat-affected zone in a laser-assisted mechanical micromachining process," International Journal of Machine Tools and Manufacture, vol. 48, no. 9, pp. 994-1004, 2008. 
[16] J. C. Hung, B. H. Yan, H. S. Liu, and H. M. Chow, "Microhole machining using micro-EDM combined with electropolishing," Journal of Micromechanics and Microengineering, vol. 16, no. 8, pp. 1480-1486, 2006.

[17] I. Yang, M. S. Park, and C. N. Chu, "Micro ECM with ultrasonic vibrations using a semi-cylindrical tool," International Journal of Precision Engineering and Manufacturing, vol. 10, no. 2, pp. 5-10, 2009.

[18] T. Endo, T. Tsujimoto, and K. Mitsui, "Study of vibrationassisted micro-EDM-The effect of vibration on machining time and stability of discharge," Precision Engineering, vol. 32, no. 4, pp. 269-277, 2008.

[19] S. Koshimizu and I. Iansaki, "Hybrid machining of hard and brittle materials," Journal of Mechanical Working Technology, vol. 17, pp. 333-341, 1988.

[20] T. B. Thoe, D. K. Aspinwall, and M. L. H. Wise, "Review on ultrasonic machining," International Journal of Machine Tools and Manufacture, vol. 38, no. 4, pp. 239-255, 1998.

[21] D. Kremer, S. M. Saleh, S. R. Ghabrial, and A. Moisan, "The State of the Art of Ultrasonic Machining," CIRP AnnalsManufacturing Technology, vol. 30, no. 1, pp. 107-110, 1981.

[22] X. Q. Sun, T. Masuzawa, and M. Fujino, "Micro ultrasonic machining and self-aligned multilayer machining/assembly technologies for 3D micromachines," in Proceedings of the IEEE Micro Electro Mechanical Systems (MEMS '96), pp. 312317, 1996.

[23] B. Ghahramani and Z. Y. Wang, "Precision ultrasonic machining process: a case study of stress analysis of ceramic $\left(\mathrm{Al}_{2} \mathrm{O}_{3}\right)$," International Journal of Machine Tools and Manufacture, vol. 41, no. 8, pp. 1189-1208, 2001.

[24] T. Masuzawa and H. K. Tönshoff, "Three-dimensional micromachining by machine tools," CIRP Annals - Manufacturing Technology, vol. 46, no. 2, pp. 621-628, 1997.

[25] K. Egashira, T. Masuzawa, M. Fujino, and X. Q. Sun, "Application of USM to micromachining by on-the-machine tool fabrication," International Journal of Electrical Machining, no. 2, pp. 31-36, 1997.

[26] K. Egashira and T. Masuzawa, "Microultrasonic machining by the application of workpiece vibration," CIRP AnnalsManufacturing Technology, vol. 48, no. 1, pp. 131-134, 1999.

[27] C. Y. Khoo, E. Hamzah, and I. Sudin, "A review on the rotary ultrasonic machining of advanced ceramics," Jurnal Mekanikal, no. 25, pp. 9-23, 2008.

[28] M. Komaraiah and P. N. Reddy, "A study on the influence of work piece properties in ultrasonic machining," International Journal of Machine Tools and Manufacture, vol. 33, no. 3, pp. 495-505, 1993.

[29] A. R. Jones and J. B. Hull, "Ultrasonic flow polishing," Ultrasonics, vol. 36, no. 1-5, pp. 97-101, 1998.

[30] A. C. Wang, B. H. Yan, X. T. Li, and F. Y. Huang, "Use of micro ultrasonic vibration lapping to enhance the precision of microholes drilled by micro electro-discharge machining," International Journal of Machine Tools and Manufacture, vol. 42, no. 8, pp. 915-923, 2002.

[31] R. Singh and J. S. Khamba, "Ultrasonic machining of titanium and its alloys: a review," Journal of Materials Processing Technology, vol. 173, no. 2, pp. 125-135, 2006.

[32] T. Kuriyagawa, T. Shirosawa, O. Saito, and K. Syoji, "Micro ultrasonic abrasive machining for three-dimensional millistructures of hard-brittle materials," in Proceedings of the 16th ASPE Annual Meeting, pp. 525-528, 2001.

[33] A. Curodeau, J. Guay, D. Rodrigue, L. Brault, D. Gagné, and L. P. Beaudoin, "Ultrasonic abrasive $\mu$-machining with thermoplastic tooling," International Journal of Machine Tools and Manufacture, vol. 48, no. 14, pp. 1553-1561, 2008.

[34] K. Egashira, T. Taniguchi, H. Tsuchiya, and M. Miyazaki, "Microultrasonic machining using multitools," in Proceedings of the 7th International Conference on Progress Machining Technology (ICPMT '04), pp. 297-301, December 2004.

[35] Instruction manual for stationary SONIC-MILL 500W Model 2002 (U.S.A).

[36] F. B. Gary, Book on Non Traditional Manufacturing Processes, Marcel Dekker, New York, NY, USA, 1987.

[37] R. Jadoun, K. Pradeep, and B. K. Mishra, “Taguchi’s optimization of process parameters for production accuracy in ultrasonic drilling of engineering ceramics," in Production Engineering, vol. 3, pp. 243-253, German Academic Society for Production Engineering, Springer, Berlin, Germany, 2009.

[38] R. S. Jadoun, P. Kumar, B. K. Mishra, and R. C. S. Mehta, "Optimization of process parameters for ultrasonic drilling of advanced engineering ceramics using the Taguchi approach," Engineering Optimization, vol. 38, no. 7, pp. 771-787, 2006.

[39] M. Adithan and V. C. Venkatesh, "Study of the performance characteristics of an ultrasonic drilling head," Wear, vol. 33, no. 2, pp. 261-270, 1975.

[40] Z. Yu, X. Hu, and K. P. Rajurkar, "Influence of debris accumulation on material removal and surface roughness in micro ultrasonic machining of silicon," CIRP AnnalsManufacturing Technology, vol. 55, no. 1, pp. 201-204, 2006.

[41] Z. Y. Yu, K. P. Rajurkar, and A. Tandon, "Study of 3D microultrasonic machining," Journal of Manufacturing Science and Engineering, Transactions of the ASME, vol. 126, no. 4, pp. 727732,2004

[42] J. J. Boy, E. Andrey, A. Boulouize, and C. Khan-Malek, "Developments in microultrasonic machining (MUSM) at FEMTO-ST," International Journal of Advanced Manufacturing Technology, vol. 47, no. 1-4, pp. 37-45, 2010.

[43] X. Q. Sun, T. Masuzawa, and M. Fujino, "Micro ultrasonic machining and its applications in MEMS," Sensors and Actuators, A, vol. 57, no. 2, pp. 159-164, 1996.

[44] K. Egashira, K. Mizutani, and T. Nagao, "Ultrasonic vibration drilling of microholes in glass," CIRP Annals_Manufacturing Technology, vol. 51, no. 1, pp. 339-342, 2002.

[45] C. Zhang, R. Rentsch, and E. Brinksmeier, "Advances in micro ultrasonic assisted lapping of microstructures in hard-brittle materials: a brief review and outlook," International Journal of Machine Tools and Manufacture, vol. 45, no. 7-8, pp. 881-890, 2005.

[46] T. Li and Y. B. Gianchandani, "A die-scale micromachining process for bulk PZT and its application to in-plane actuators," in Proceedings of the 18th IEEE International Conference on Micro Electro Mechanical Systems (MEMS '05), pp. 387-390, February 2005.

[47] X. Hu, Z. Yu, and K. P. Rajurkar, "State-of-the-art review of micro ultrasonic machining," in Proceedings of the International Conference on Manufacturing Science and Engineering (MSEC '06), October 2006. 

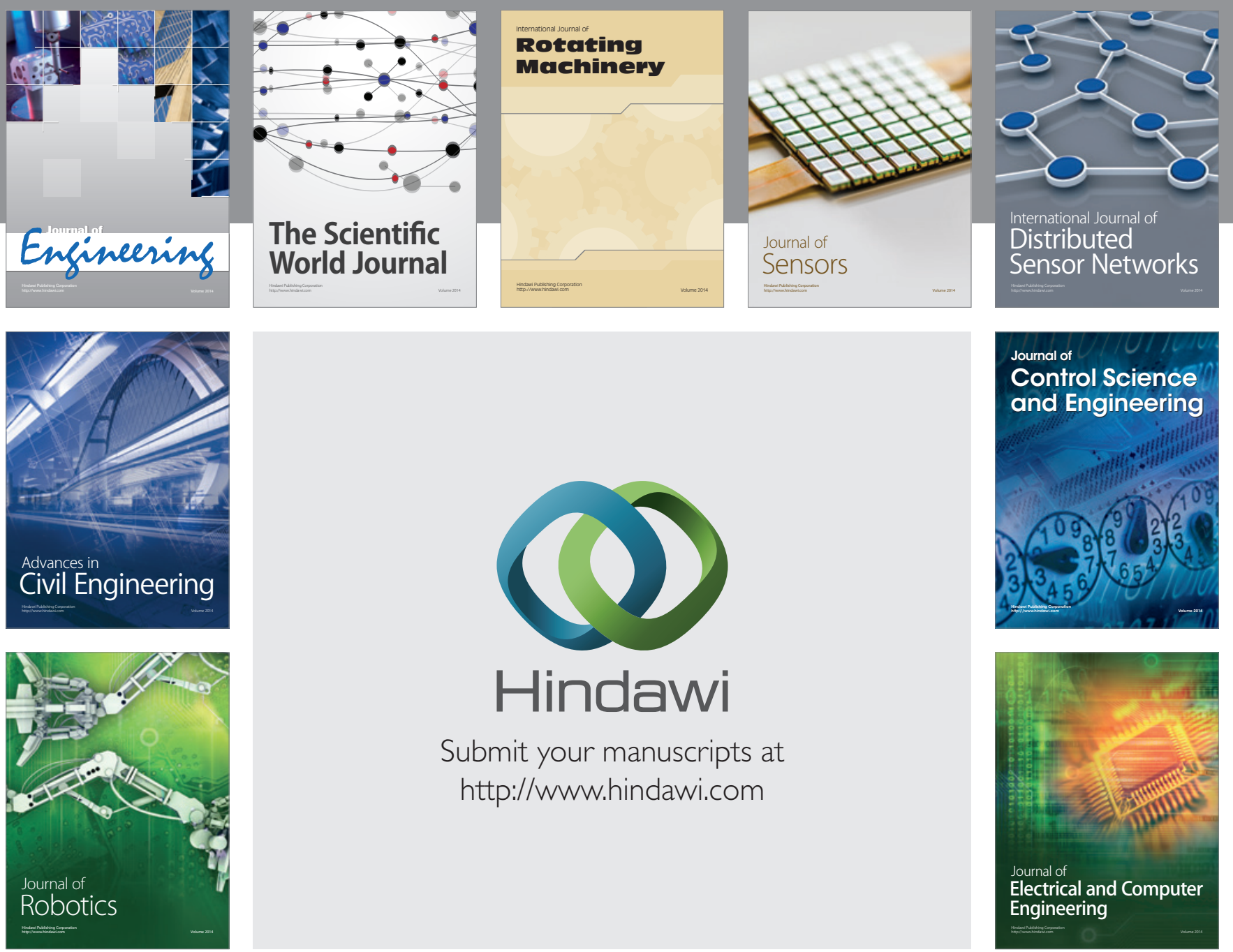

Submit your manuscripts at

http://www.hindawi.com
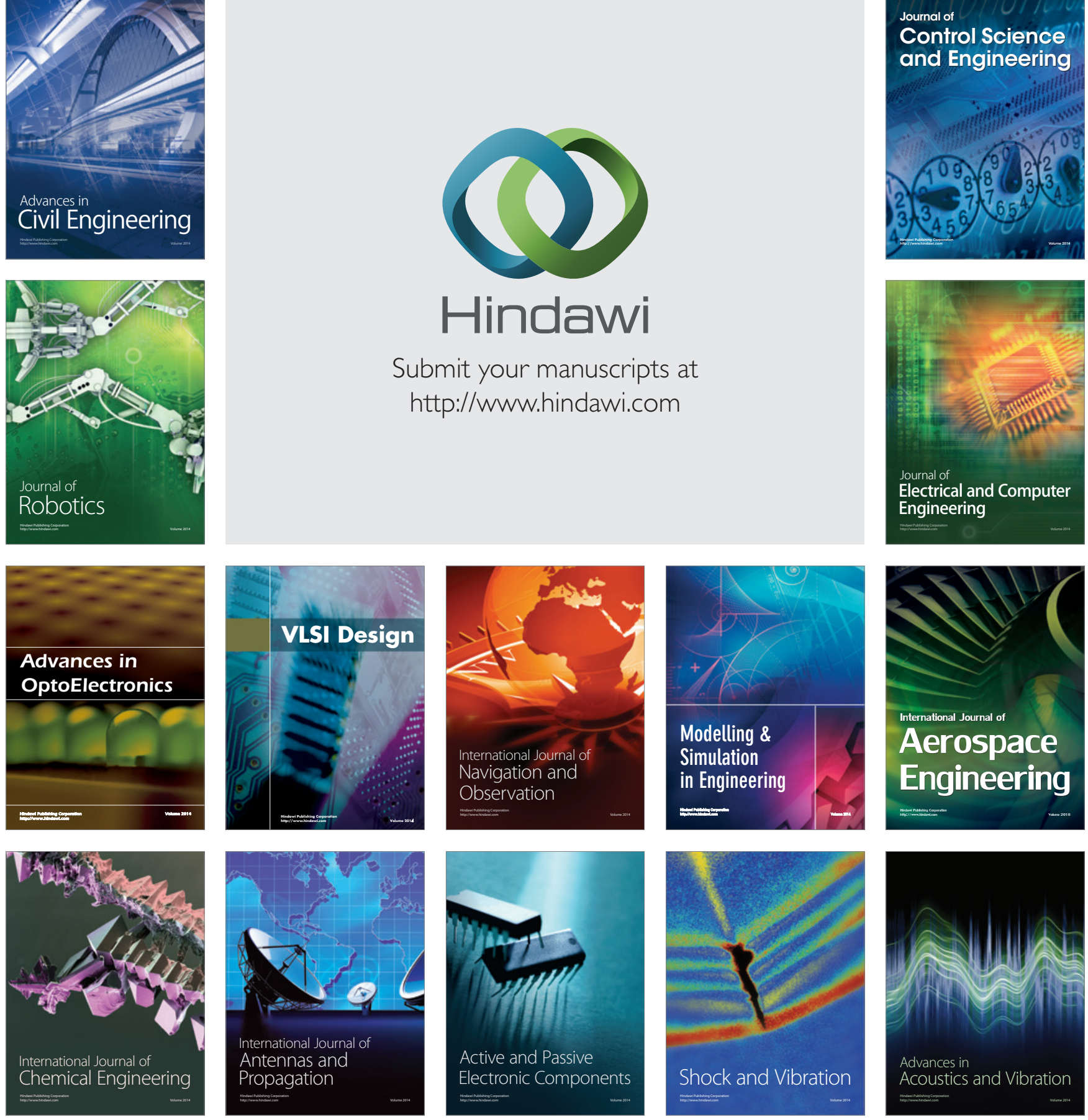